El Antoniano. 2018; 133: 1-26

Recepción: 18.11.2017

Aprobación: 25.05.2018

\title{
ACTIVIDADES QUE GENERAN IMPACTO AMBIENTAL EN EL PARQUE ARQUEOLÓGICO DE SAQSAYWAMAN
}

\author{
Álvarez Moscoso M. Esther ${ }^{1}$ mestheralv@gmail.com \\ Cruz Miranda, Luciano ${ }^{1}$. lucianojul@yahoo.com \\ Yanque Yucra, Percy ${ }^{1}$. percyyanque@yahoo.es \\ Quispe Montoya, Gustavo ${ }^{1}$.ragustav@yahoo.es \\ Gil Mora Juan Eduardo ${ }^{1}$.mundoandino2005@yahoo.es \\ Kjuro Arenas, Samuel ${ }^{1}$. ab302411@hotmail.com \\ ${ }^{1}$ Universidad Nacional de San Antonio Abad del Cusco. Cusco, Perú.
}

\section{RESUMEN}

Saqsaywaman declarado como Patrimonio Cultural de la Nación por Ley № 23765 y delimitado mediante Resolución Directoral Nacional $N^{\circ} 829 /$ INC posee un área de 2,997.256 ha, constituye un escenario de recepción para turistas nacionales y extranjeros.

El objetivo del trabajo fue identificar las actividades que generan impacto ambiental en el Parque Arqueológico de Saqsaywaman. Se aplicó el método inductivo-deductivo y diseño correlacional. Para la evaluación y valoración de los impactos se utilizaron métodos convencionales como las matrices causa/efecto y el método Battelle; así mismo; la encuesta y la investigación participativa fueron utilizados para la obtención de información socioeconómica.

El Parque Arqueológico de Saqsaywaman (PAS) está sujeto a serios impactos ambientales debido a las actividades antrópicas como la invasión del área intangible en una superficie mayor a 177 ha; extracción de leña, deforestación, incendios y quemas, erosión de suelos, construcción de trochas carrozables, vías para el paseo en bicicleta (biking) y el paseo a caballo (horse riding), senderos peatonales, extracción de materiales de construcción (canteras), elaboración de yeso y cal; actividades que son objeto de análisis y evaluación.

Las actividades económicas que generan impactos en el PAS son: la actividad turística escasamente planificada con controles inadecuados; la invasión del área intangible, la construcción de trochas carrozables; la extracción de materiales de construcción, leña y especies de flora y fauna; las quemas e incendios; la actividad agrícola en zonas intangibles y la pecuaria con introducción de especies exóticas y otros. Últimamente actividades introducidas como paseo en bicicleta y paseo a caballo no tienen un adecuado control, generan erosión y deterioro paisajístico. El estudio propone un ordenamiento territorial, adecuado control de las actividades deteriorantes y, la implementación de un jardín botánico.

Palabras clave: Impactos ambientales, jardín botánico, zonas de vida natural, indicador ambiental.

\section{ABSTRACT}

Saqsaywaman declared as Cultural Heritage of the Nation by Law $N^{\circ} 23765$ and delimited by Directorial Resolution N'829/INC involves an area of 2,997.256 ha, is a scenario of 
reception for local, national and foreign visitors.

The aim of this study was to identify the activities that generate environmental impact in the Archaeological Park of Sacsaywaman. We applied the inductive-deductive scientific method, and correlational design. The environmental evaluation applied for the valuation of impacts were methods such as: linear and band transects; cause-effect matrix; and the Battelle method; at the same time; the survey and participatory research were used for the generation of socio-economic information. The Archaeological Park of Sacsaywaman (PAS) is affected by severe environmental impacts due to anthropogenic activities such as the invasion of the intangible area in approximately $177 \mathrm{ha}$; extraction of firewood, fire and burning, deforestation, soil erosion, construction of roads, tracks for the bike riding (biking) and the horseback riding, pedestrian paths, extraction of construction materials (quarries), gypsum and lime processing; activities that are subject to analysis and evaluation

The economic activities that generate impacts in the Archaeological Park of Saqsaywaman are: the scarcely planned tourist activity with inadequate controls; the invasion of the intangible area, the construction of carriage trails; the extraction of construction materials, firewood and species of flora and fauna; the burning and fires; the agricultural activity in intangible zones and the cattle raising with introduction of exotic species and others. Lately activities introduced as bike ride and horseback ride that do not have adequate control and generate erosion and deterioration of the landscape.

In conclusion, the activities that generate the most negative impacts are: urban expansion with invasion of intangible areas; agricultural activity with the use of agrochemicals; livestock; burns and fires; collection of fuelwood; construction of roads and pedestrian paths; activities of recreation little planned and without adequate control as the biking and horse riding that generate soil erosion. The study proposes a territorial ordering, adequate control of the deteriorating activities and, the implementation of a botanical garden.

Key words: environmental impacts, botanical garden, natural life zones, environmental indicator.

\section{INTRODUCCIÓN.}

El parque arqueológico de Saqsaywaman (PAS) constituye uno de los principales componentes del circuito turístico denominado City Tour, razón por la que dentro del parque se desarrollan actividades económicas como agricultura, ganadería, extracción de minería no metálica, mercados artesanales, hospedaje, restaurantes, acciones que coadyuvan a la instalación y expansión urbana al interior del parque a pesar de las restricciones legales. Como consecuencia de estas actividades se viene generando diferentes efectos como la alteración del paisaje, erosión del suelo, deterioro de la cubierta vegetal, invasión del área intangible, así como la pérdida de biodiversidad; contaminación por la generación de residuos sólidos, pérdida de la calidad de los cursos de agua, deficiente acceso a servicios básicos, etc. Por lo que es de interés e importancia identificar las diferentes actividades que se desarrollan al interior del PAS y que vienen generando impactos directos e indirectos en la conservación de este importante patrimonio cultural; los resultados del estudio permitirán tomar acciones y medidas de conservación que posibiliten una gestión adecuada del PAS que impulse una actividad turística sostenible, por lo que la presente investigación pretende proponer una herramienta de gestión para el PAS.

\section{MÉTODOLOGÍA.}

Los métodos científicos utilizados en el estudio son el deductivo y el inductivo, con ambos métodos se conduce a 
colegir conclusiones; en el caso del método deductivo se considera el conocimiento general y a partir de él se particulariza para aspectos locales; para el presente estudio, tanto del análisis de la información secundaria respecto de las características del PAS; las normativas de su creación, las actividades legalmente autorizadas y el plan de manejo se infiere que las actividades con escaso control, el turismo no planificado, las actividades no autorizadas, generan impactos que son evaluados y a partir de la valoración de los mismos se obtienen conclusiones para casos de la realidad local; mediante éste método se precisan que las conclusiones a las que se arriba son una consecuencia de premisas señaladas en normas 0 regulaciones nacionales vigentes, como es el caso de la normatividad que crea el PAS; en cambio en el caso del método inductivo, en base a observaciones y registro de los hechos evaluados en campo, el análisis y la clasificación de los mismos, se procura obtener conclusiones generales para el objeto de análisis, esto es, los impactos ambientales.

De otro lado, el Diseño Correlacional, implica la recolección de datos con la intención de determinar la subsecuente relación entre ellos; esto ha sido utilizado mediante la obtención de resultados empleando matrices de evaluación y a partir de dichos valores obtenidos, se efectúan las correlaciones correspondientes. Se trata también de la evaluación de las relaciones existentes entre las causas que generan los impactos que deterioran la calidad de los recursos y ecosistemas existentes en el PAS, sean éstas puramente correlacionales 0 relaciones causales. En estos diseños lo que se mide es la relación entre variables en un tiempo determinado; en este caso para obtener las valoraciones de los impactos utilizando las matrices y las probables causas que generan impactos ambientales.

Para la valoración de los impactos, se emplearon metodologías convencionales tales como: matriz causa/efecto y matriz de Batelle; éstos métodos para la valoración del impacto ambiental (Canter, 1999); además se utilizó la encuesta y el dialogo participativo para la obtención de datos socioeconómicos.

\section{RESULTADOS Y DISCUSIÓN.}

\section{ECOLOGIA DEL PARQUE ARQUEOLOGICO DE SAQSAYWAMAN. \\ 1.1. Clima.}

En el PAS se distinguen dos tipos de clima:

- Lluvioso frio con Invierno seco

- Semiseco semifrio con invierno seco.

Tabla 1: Promedios de temperatura y precipitación

\begin{tabular}{|c|c|c|}
\hline Meses & Temperatura $\left({ }^{\circ} \mathrm{C}\right)$ & Precipitación (mm \\
\hline Enero & 12.7 & 156.5 \\
\hline Febrero & 12.8 & 125.5 \\
\hline Marzo & 12.5 & 36.0 \\
\hline Abril & 12.4 & 5.3 \\
\hline Mayo & 11.1 & 4.5 \\
\hline Junio & 10.5 & 12.1 \\
\hline Julio & 10.2 & 7.5 \\
\hline Agosto & 11.1 & 11.2 \\
\hline Septiembre & 12.2 & 53.5 \\
\hline Octubre & 13.1 & 65.3 \\
\hline Noviembre & 12.6 & 102.0 \\
\hline
\end{tabular}




\begin{tabular}{|c|c|c|}
\hline Promedio mensual & 11.9 & \\
\hline Total anual & & 684.2 \\
\hline
\end{tabular}

Fuente: Estación Meteorológica de la UNSAAC. 2012.

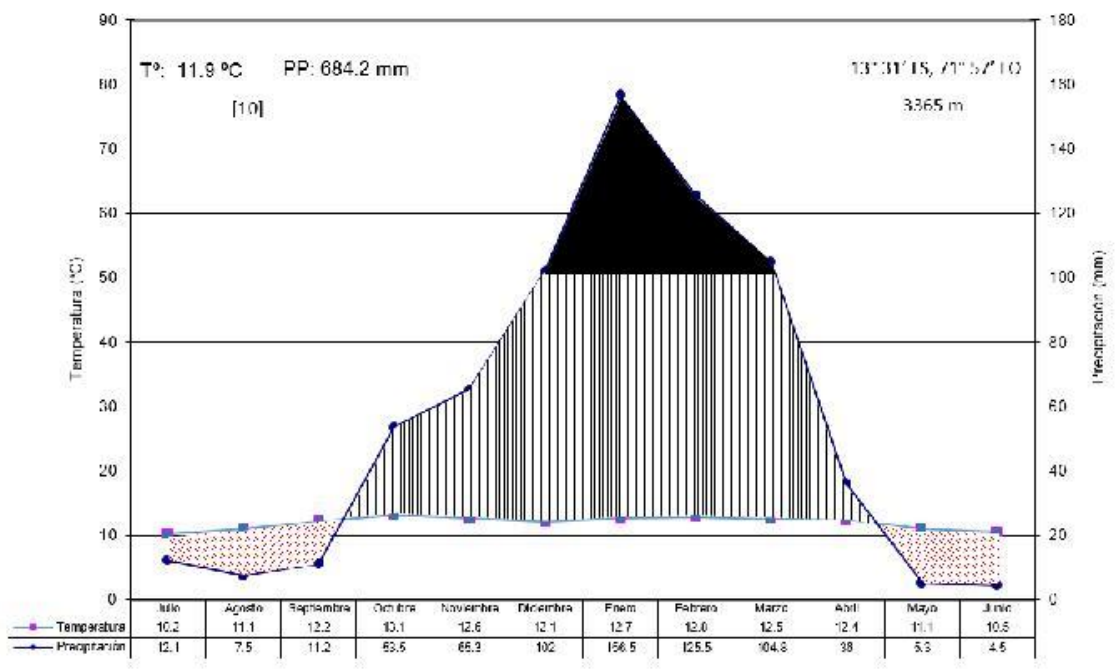

Figura 1. Climatodiagrama Estación Meteorológica Luis Olazo - Perayoc, UNSAAC Fuente: Elaborado en base a la tabla1. 
El área de estudio, presenta dos épocas marcadas un periodo con ausencia de precipitaciones (secas) de mayo a setiembre y un periodo de precipitaciones desde octubre hasta abril incrementándose estas precipitaciones de diciembre a marzo, registrándose los valores más altos de precipitación en el mes de enero.

\subsection{Zonas de Vida Natural.}

Las Zonas de Vida Natural descritas a continuación se basan en el Mapa Ecológico elaborado por ONERN, 1976, el mismo que se basa en el sistema de clasificación de Holdridge; empleando dichos conceptos y los trabajos de campo en el ámbito de estudios, se determinaron las siguientes Zonas de Vida Natural:

\section{a: Páramo muy Húmedo Subalpino Subtropical (pmh-SaS):}

Abarca las áreas más altas del Parque, por encima de los 3900 m. s. n. m. Forman parte los cerros Senqa, Fortaleza y Salqantay. Caracterizadas por una topografía con pendientes superiores al $35 \%$ presentando en muchos casos afloramientos rocosos debido a la erosión.

Los suelos son demasiado superficiales que corresponden a litosoles y un estrato delgado de suelos orgánicos allí donde no hubo disturbamiento.

La vegetación característica es la cespitosa formada por poaceas de las especies: Festuca heterophilla; Calamagrostis intermedia; Stipa ichu; Muhlembergia ligularis; Alchemilla pinnata; Aciachne pulvinata y otros. No observándose vegetación arbórea ni arbustiva.

Las características climáticas son bastante frías, con ocurrencia de fuertes heladas entre mayo y agosto.

\section{b: Bosque Húmedo Montano} Subtropical (bh-MS):

Cubre áreas ubicadas altitudinalmente entre los 3500 y 3900 m. s. n. m. Es la Zona de Vida más extensa del Parque y la que mayor presión antrópica ha sufrido debido a la actividad agrícola, pecuaria, expansión urbana, turismo, etc.

Entre las características climáticas podemos mencionar que la temperatura media anual máxima es de $13.5^{\circ} \mathrm{C}$ (Estación de Perayoc) y la media anual mínima es de $3.5^{\circ} \mathrm{C}$. Las temperaturas extremas fluctúan entre 220 C(octubre) a $3 \stackrel{\circ}{ }$ bajo cero (julio). La meseta de Saqsaywaman y las planicies de Yuncaypata y Socorro constituyen los lugares más fríos por encontrarse expuestos a masas de aire gélidos, con la consiguiente manifestación de heladas fuertes.

El relieve presenta una topografía ondulada y suave con excepción de las pequeñas quebradas formados por los riachos como el Saphy, Inquilmayo y Cachimayo. Predominantemente la roca de mayor abundancia es la caliza de origen marino y que pertenece a la formación Yuncaypata; aunque también se observan afloramientos de diorita, lutita, areniscas y sedimentos formados por yeso.

Considerando la vegetación y la flora; esta es la Zona de Vida con mayor diversidad, aunque la frecuencia, la densidad y la cobertura sean relativamente bajas debido al impacto generado por las acciones antrópicas. Se observa tres características vegetacionales, esto en razón a peculiaridades edáficas, de humedad, altitudinales y accesibilidad.

En la parte alta existe predominio de poaceas y ausencia de especies arbóreas, pero sí se aprecia la presencia de vegetación subarbustiva leñosa tanto espinosa como inerme, tales como: Austrocylindropuntia floccosa, el roque (Colletia spinossisima); chinchircuma (Mutisia hirsuta); Checche (Berberis 
carinata); llaulli (Barnadesia horrida); tayanca (Baccharis odorata); Tajetes sp; Gnaphalium spp

La parte media se caracteriza por la presencia de especies arbóreas como el Chachacomo (Escallonia resinosa); queuña (Polylepis incana); qolle (Buddleja coriacea); quishuar (Buddleja incana); molle (Schinus molle); arbustos como el cantu (Cantua buxifolia); mutuy (Senna birrostris); chilca (Baccharis polyanta) y la presencia de especies exóticas como el eucalipto; el pino, el ciprés y la retama. La vegetación en esta Zona se muestra fuertemente impactada por la agricultura, colección de material para leña y la ganadería.

El tercer espacio está constituido por la vegetación presente en los oquedales a los que difícilmente puede calificarse como "relictos", a pesar de ello, aún la abundancia y la cobertura son muy importantes y constituyen lo que denominaríamos los "bancos genéticos y de germoplasma" del Parque Arqueológico de Saqsaywaman. Entre otras especies, además de las ya citadas, se halla el lloque (Kageneckia lanceolata), especie sumamente importante por ser de múltiple uso, pues es utilizada en cestería, para la construcción de aperos agrícolas y como material combustible.

Esta Zona de Vida evidencia suelos aptos para la agricultura tanto de riego como de secano; sin embargo, la inadecuada tecnología de riego (por inundación), el empleo de agroquímicos, etc. han conducido a un franco proceso de deterioro de la capa fértil. Los principales cultivos son la papa, oca, olluco, haba, cebada cervecera, cebada forrajera, alfalfa $\mathrm{y}$, excepcionalmente verduras como la lechuga, repollo, zanahoria y cebolla.

\section{c: Bosque Seco Montano Bajo Subtropical (bsMBS). \\ Comprende el extremo sur del Parque,}

particularmente la parte media y baja de la microcuenca del río Cachimayo, hoy altamente deteriorado y urbanizada.

La vegetación primaria ha sido fuertemente deteriorada y sustituida por los cultivos; sin embargo, puede apreciarse la retama (Spartium junceum), pacpa (Agave americana) y plantaciones de eucalipto, p'ataquiska (Austrocylindropuntia subulata).

\section{EVALUACIÓN DE IMPACTO AMBIENTAL.}

\subsection{Acciones que generan}

impactos. a. Actividad Agrícola

Las evaluaciones de campo nos permiten colegir que la agricultura es la responsable de los mayores impactos. A pesar de existir restricción en el uso de instrumentos y equipos agrícolas, maquinaria e insumos agrícolas; sin embargo, en Saqsaywaman se emplea maquinaria pesada como el tractor, en aproximadamente en el $7 \%$ de las parcelas agrícolas y en todas las parcelas utilizan agroquímicos.

La actividad agrícola debido al empleo de surcos en favor de la pendiente, riego por inundación y escaso tiempo de descanso otorgado a la parcela, provoca erosión laminar, por lo tanto, pérdida de suelo fértil. A este hecho es necesario agregar la falta de un asesoramiento en el control fitosanitario de los productos utilizados por los agricultores asentados en el PAS.

Debido al minifundio existente en la mayoría de las comunidades campesinas del Parque, se han iniciado, el empleo de suelos no agrícolas para el cultivo de ciertas especies generando un escaso rendimiento y alto deterioro del recurso suelo. Es preciso anotar que, en varios sectores del Parque han sido construidos pequeñas represas tanto con fondo de concreto como pozos en piso de tierra; 
ambas construcciones tienen como propósito el almacenamiento de agua sea de precipitación pluvial como de manantes para la irrigación; estas construcciones no cuentan con la autorización ni una dirección técnica adecuada.

Es importante señalar que debido a la escasez de áreas agrícolas los cultivos son instalados en áreas que tienen aptitud para pastos y en áreas de protección, que corresponden, a suelos con pendientes superiores al 30\%, por lo tanto, son suelos susceptibles a la erosión por cárcavas.

\section{b. Actividad pecuaria}

La actividad pecuaria se halla distribuida en todo el territorio del Parque, aunque con mayor incidencia en la parte media y alta. La introducción de ganado exótico, particularmente ovino induce al sobrepastoreo y constituye un factor que incita a la práctica de las quemas, aunque de pequeñas áreas para la obtención de pasto tierno mediante el rebrote con fines de alimentación de este ganado. Un aspecto remarcable en la parte media del Parque es la presencia de ganado caprino, aun cuando en el momento actual tiene incidencia baja, empero, de no ser erradicado puede acelerar el proceso de erosión actual.

\section{c. Quemas}

La quema no es una práctica usual en la actividad agrícola y/o pecuaria de los habitantes del Parque. Las observaciones de campo y la información recopilada mediante encuestas y entrevistas evidencian que sólo en forma esporádica se practica la quema. La actividad de la ganadería ovina es la que induce a la quema en pequeñas parcelas. Se ha observado en las micro cuencas de los ríos Inquilmayo, Ukukuchayoc y Cachimayo pequeñas extensiones afectadas por el fuego y que, aparentemente, se generaron en incendios, afectando la vegetación arbustiva y sub arbórea en aproximadamente 10 ha.

\section{d. Obtención de leña.}

A pesar de que en algunas comunidades rurales y en casi todos los asentamientos urbano- marginales cuentan con el servicio de energía eléctrica, la leña continúa siendo la principal fuente de energía para la cocción de alimentos, tanto en la parte media como baja del Parque. Este hecho induce a que la vegetación leñosa se vea afectada tanto en su frecuencia y densidad. Especies importantes y representativas del Parque tales como Escallonia resinosa (chachacomo), Escallonia mirtilloides (t'asta), Kageneckia lanceolata (lloque), Polylepis spp (queuña), Cytarexylum herrerae (huayruro cusqueño), etc. han sido casi eliminados. En la parte alta, las especies más afectadas son el Buddleia cariacea (qolle), Buddleia incana (kishuar) y el Tetraglochin cristatum (Kanlli), a pesar de que en esta zona la bosta de ganado vacuno y ovino constituyen elementos importantes como fuentes de energía.

\section{e. Turismo y recreación.}

Una de las actividades importantes desarrolladas es la del turismo y el esparcimiento de la población proveniente de la ciudad del Cusco. El turismo permite apreciar los principales monumentos arqueológicos como la explanada de Saqsaywaman (sector de los baluartes), k'enqo y Tambomachay. El impacto del turismo guiado es apreciable y no involucra a la población local, por lo tanto, no constituye un beneficio efectivo para las poblaciones asentadas dentro del Parque; es más, la opinión de los comuneros es que el Parque constituye una situación restrictiva en algunas de sus actividades.

La recreación es otro aspecto importante que genera impactos negativos, generando la acumulación de residuos sólidos en áreas arqueológicas. El uso de áreas planas dentro de los monumentos 
como canchas de fulbito y fútbol, etc.

Un aspecto importante es la gran concentración de personas durante la escenificación del Inti Raymi. La información sustenta que esta conmemoración también genera los mayores impactos, no sólo disturba los componentes líticos del monumento, sino también la flora leñosa sufre las consecuencias debido a que son empleados como combustible; igualmente la obtención de terrones para la preparación de las comúnmente denominadas "watias", generan y/o facilitan la erosión del suelo; además, del uso de acémilas que genera deterioro tanto en el suelo como de la vegetación.

\section{f. Expansión urbana.}

El incremento poblacional del Cusco ha ejercido, desde hace más de 25 años, fuerte presión en las áreas colindantes del Parque y dentro del propio Parque. La expansión urbana es prácticamente caótica y puede generar mayores impactos, si acaso no se consideran estudios serios de ordenamiento territorial, pues actualmente esta población ejerce sustantiva presión sobre los recursos existentes en el Parque en términos de leña, piedra, pasto, agua, suelos, etc. Pues actualmente existen serios problemas de saneamiento en lo que respecta al abastecimiento de agua de consumo, manejo de residuos sólidos y tratamiento de aguas residuales. Debido a un escaso control y administración en los límites del PAS; inicialmente hubo invasión desde la periferia hacia el interior del Parque; sin embargo en los últimos 25 años, no sólo la invasión se ha acrecentado; sino que, se construyeron asentamientos de neo formación rompiendo toda norma que prohibía la construcción de viviendas y actividades de comercio dentro del PAS. Esta ilegal actividad trajo consigo una rápida densificación de la zona. La presencia de una zona comercial con tiendas de artesanías, abarrotes, restaurants con tendencia a un crecimiento en número de negocios e infraestructura continúa generando mayores impactos.

\section{g. Generación de residuos sólidos.}

Este tipo de contaminación va en aumento, debido al cambio de los estilos de vida y al crecimiento demográfico que se incrementa por el establecimiento de asentamientos rurales y urbanos y los impactos de la actividad turística, además la posibilidad de eliminarlos se hace cada vez más difícil debido a la falta de planificación y concientización de los habitantes; no existe ningún sistema de recojo de los residuos sólidos generados y afecta a los lechos de ríos y al suelo además de las implicancias en la salud.

\section{h. Deterioro del suelo.}

Existen taludes con pendientes altas que forman las quebradas de Saphy y Cachimayo las mismas que se encuentran principalmente en proceso de erosión hidrica como consecuencia de las precipitaciones pluviales y debido al grado de fracturamiento de los afloramientos rocosos (areniscas, microdioritas, calizas), al encontrarse expuestas y sin cobertura vegetal. La accion antropica que se evidencia son las canteras abandonadas, la expansión urbana y la extraccion de ichu para construccion contribuyen al deterioro.

Las principales causas determinadas del deterioro del suelo son:

> La sistemática y permanente deforestación de la cubierta vegetal tanto arbórea, arbustiva y cespitosa; este hecho no sólo ha conducido a que el agua de escorrentía y de la precipitación corran sobre el suelo desnudo arrastrando el material orgánico e inorgánico existente, sino que ha afectado a los acuíferos haciendo que desciendan el volumen de los manantes. 
$>$ Las técnicas agrícolas indecuadas como el empleo de surcos a favor de la pendiente y el escaso tiempo de descanso otorgado a las parcelas provoca la erosion hidrica, además el riego no controlado, generan una erosion gravitacional en cárcavas, apreciandose estos efectos en algunos sectores como Salkantay, Yuncaypata,

Huayllarqocha,Tambomachay, provocando la pérdida de la capa arable.

$>$ Policultivos en laderas sin trabajos de conservacion de suelos.

$>\quad$ La expansion urbana, las actividades comerciales y turisticas inciden de manera acelerada en el deterioro del PAS, generando zonas de alto Riesgo por desestabilizacion de suelos, que pueden afectar la geodinamica externa en la zona.

$>$ Otra causa es el crecimiento de la población, tanto en número de habitantes por comunidad como la formación de nuevos asentamientos humanos posibilitando que

las áreas destinadas a la practica agrícola sea, en principio más pequeña llegándose

al microfundio y haciendo que el tiempo de descanso, que se suele otorgar a la parcela, sea cada vez menor; consecuentemente, la actividad agrícola intensiva ha conducido no sólo al empobrecimiento del suelo sino a una erosión laminar.

$>$ El riego practicado es por inundación, esta práctica, cuando no se halla adecuadamente controlada, arrastra los nutrientes y el sedimento.

$>\quad$ La construcción de caminos peatonales, trochas carrozables y otros accesos han favorecido la circulación del agua que ha contribuido a su vez, en la erosión.

$>$ Las quemas y los incendios, son factores que provocan erosión.

$>$ Extraccion de material arcilloso para la fabricacion de artesanias.

$>$ Extraccion de suelo rico en materia orgánica así como la extracción de las denominadas "champas" para uso en jardineria.

\section{i. Contaminación de fuentes} hídricas.

Se evidencia notable reducción del caudal de las fuentes hídricas en las cuencas por captación de aguas para consumo humano, y el inadecuado uso en actividades de riego.

La contaminación por evacuación de aguas servidas a riachuelos, manantes, humedales en el PAS es permanente, (caracterizada principalmente por contener sustancias biodegradables y compuestos químicos domésticos como detergentes, compuestos de cloro como resultado del lavado de ropa, buses, taxis de servicio público).

Perdida de manantes como consecuencia del cambio de uso de suelos, forestación con especies exóticas, degradación de suelos por sobrepastoreo, compactación de suelos y empleo de agroquímicos.

La no gestión de residuos sólidos, dispuestos o arrojados directamente en cuerpos de agua y áreas abandonadas. Igual ocurre con el excremento de animales (caballos).

El proceso de destrucción del sistema de reservorios Inka, Sirena Qocha - Sector de Tambillo con inminente peligro de pérdida irremediable, por robo de las piezas líticas que la conformaban.

\subsection{INDICADORES DE IMPACTO AMBIENTAL.}

La alteración de los ecosistemas, así como la destrucción de los hábitats provocados por las acciones 
mencionadas en el acápite anterior han afectado a especies representativas y conspicuas, tales como los cérvidos, aves, batracios y peces que son los grupos más afectados. En efecto, las consecuencias de la alteración de la cubierta vegetal por la actividad agrícola y pecuaria, han alterado el régimen de las aguas y la densidad de las especies que forman los bosques altoandinos. A continuación, se presentan un resumen de acciones que generan impactos ambientales. 


\section{a. P rá c t i c a s de manejo y uso de recursos naturales en el PAS}

Tabla 2. Prácticas de manejo y uso de recursos naturales en el PAS.

\begin{tabular}{|l|c|}
\hline \multicolumn{1}{|c|}{ Práctica de Manejo } & Cualificación \\
\hline Acceso del público & 01 \\
\hline Instalación de obras recreativas & 02 \\
\hline Uso recreativo intensivo & 03 \\
\hline Uso recreativo extensivo & 02 \\
\hline Turismo y recreación & 01 \\
\hline Investigación en RR.NN. & 01 \\
\hline Investigación en arqueología e historia & 01 \\
\hline Instalación de obras para la investigación & 03 \\
\hline Manejar la vida silvestre para fines estéticos, recreativos o educación & 03 \\
\hline Introducción de ganado exótico & 04 \\
\hline Modificación de hábitat de peces & 04 \\
\hline Modificación del recurso hídrico para mejorar la producción del agua & 05 \\
\hline Conducción del agua fuera del PAS & 05 \\
\hline Uso de vehículos motorizados & 03 \\
\hline Producción agrícola & 02 \\
\hline Empleo de agroquímicos & 05 \\
\hline Empleo de maquinarias (tractores) & 04 \\
\hline Obtención de leña & 03 \\
\hline Introducción de vegetación arbórea exótica & 04 \\
\hline Extracción de recursos mineros & 04 \\
\hline Asentamientos humanos de neo formación & 05 \\
\hline Uso de caballos & 03 \\
\hline Instalación de hoteles y alojamiento & 04 \\
\hline Comercio ambulatorio & 04 \\
\hline
\end{tabular}

Fuente: Elaborado en base a observaciones de campo y prácticas de manejo propuestas en la creación del PAS.

Tabla de valores:

01: Compatible

02: Generalmente compatible

03: Limitadamente compatible

04: Generalmente no compatible

05: No compatible.

El valor del Parque no sólo depende de las características y potencialidades por los que fueron propuestos en su creación, sino por la manera que éstos puedan ser utilizados, así como de las prácticas de manejo permitidos.

De las 24 prácticas, evaluadas en el cuadro precedente, 11 no son compatibles, 6 son limitadamente compatibles y 6 se hallan dentro de las prácticas compatibles. 4 prácticas (modificación del recurso hídrico, conducción del agua fuera del PAS, uso de agroquímicos y, la formación de nuevos asentamientos humanos) se hallan en el umbral de las prácticas que generan los mayores impactos y 4 que son totalmente compatibles. Seis prácticas de manejo se hallan en el valor intermedio (03), lo que significa que su ejercicio debe ser permanentemente vigilado y poseer acciones de mitigación. 


\section{b. Interrelación entre grupos de gestión y acciones.}

Tabla 3. Evaluación de Impacto Ambiental: Tipos de población y acciones.

\begin{tabular}{|l|l|l|l|l|l|l|l|l|}
\hline \hline Población Acciones & A & B & C & D & E & F & G & SUMA \\
\hline Rural & 4 & 4 & 2 & 2 & 1 & 5 & 5 & 23 \\
\hline Periurbana & 4 & 4 & 2 & 4 & 4 & 5 & 5 & 28 \\
\hline Turista & 3 & 2 & 4 & 3 & 2 & 4 & 4 & 22 \\
\hline Trabajador DRC & 2 & 2 & 4 & 3 & 2 & 4 & 4 & 21 \\
\hline ONGs & 4 & 2 & 4 & 3 & 2 & 4 & 4 & 23 \\
\hline SUMA & $\mathbf{1 7}$ & $\mathbf{1 4}$ & $\mathbf{1 6}$ & $\mathbf{1 5}$ & $\mathbf{1 1}$ & $\mathbf{2 2}$ & $\mathbf{2 2}$ & $\mathbf{1 1 7}$ \\
\hline
\end{tabular}

Fuente: Elaborado en base a observaciones de campo e información recopilada mediante encuestas.

\section{Actividades}

A: Agricultura

B: Ganadería.

C: Actividades del DDCC

D: Actividades de las ONGs

E: Expansión urbana.

Saneamiento.
Valoración

1: Muy desfavorable

2: Desfavorable

3: Habitual

4: Favorable

5: Muy favorable. F:
El cuadro precedente constituye la opinión de cinco grupos de población existentes dentro de la jurisdicción del PAS con respecto a las acciones emprendidas o que se vienen implementando.

Resulta interesante efectuar al análisis tanto respecto de cada grupo humano, es decir, una apreciación horizontal del cuadro, cuanto un análisis vertical, en el sentido de las acciones, donde las cifras más bajas significan un mayor impacto negativo.

Para un rápido análisis del cuadro podemos dividir los valores del impacto en tres grupos: desfavorable; habitual (aquella acción que no genera impactos positivos ni negativos, no modifica sustancialmente el medio ni afecta el bienestar de la población) y, favorable. En tal sentido, podemos señalar que:

Para la población rural (comunidades campesinas) las acciones que provocan mayor impacto son las desarrolladas por la Dirección Desconcentrada de Cultura de Cusco (DDCC), ONGs y la expansión urbana; esta opinión es explicable en razón de que la gestión desarrollada por la DDCC, intenta a través de sus acciones proteger el patrimonio cultural, por lo tanto, frenar las acciones de la población rural asentada dentro del Parque; de otro lado, en estas acciones de la DDCC, se involucran escasamente las comunidades campesinas del Parque; falta una adecuada difusión de las actividades y educación respecto de la importancia del Parque y que las actividades de la población como agricultura, ganadería, edificaciones, etc. deberían estar reguladas por esta Dirección.

Referente a las acciones desarrolladas por las ONGs, es en razón de que algunas de ellas favorecen a los asentamientos humanos periurbanos obteniendo y usando los recursos naturales del Parque y que se hallan en la jurisdicción comunal.

Para la población periurbana la única acción que genera impacto es la de la DDCC, esto por las mismas razones sustentadas por el sector rural.

Para los turistas y visitantes, dos son las acciones negativas que repercuten en la conservación del Parque: la ganadería y la expansión urbana. 
Para los trabajadores de la DDCC, tres son las acciones que provocan impactos negativos dentro del PAS: la agricultura, la ganadería y la expansión urbana; esta apreciación es obvia toda vez que son las tres actividades que requieren ser controladas, monitoreadas y reguladas por Ia DDCC dentro del territorio del Parque.

De otro lado se tiene la opinión de las ONGs, que sustentan que existen dos acciones importantes que deben ser consideradas por su impacto: la ganadería y la expansión urbana, lo último en razón de su distribución caótica y desordenada, así como porque usufructúan los recursos provenientes del Parque.

Es interesante señalar que para los sectores rurales y periurbanos todas las acciones desarrolladas dentro del Parque son modificatorias, ninguna acción es pasiva 0 habitual, distinguiéndose que el saneamiento y la electrificación son acciones muy favorables. Del mismo modo, la actividad agrícola, a pesar de las observaciones del equipo que desarrolla el presente trabajo, resulta siendo calificada como favorable, a excepción del grupo conformado por los trabajadores de la Dirección Desconcentrada de Cultura de Cusco.

En el análisis de las acciones, es de observar que la actividad que ocasiona el mayor impacto es la expansión urbana empleando terrenos del parque; todas las poblaciones, con excepción del sector periurbano, la califican como desfavorable 0 muy desfavorable. Otra acción que es considerada con calificación desfavorable, por tres de los cinco sectores analizados, es la ganadería; las poblaciones que opinan que constituye una acción favorable son la rural y la periurbana; ello es natural toda vez que son estos sectores los que desarrollan esta actividad dentro del Parque.

Por lo anteriormente explicado se hace necesario actuar sobre aquellas acciones que resultan siendo calificadas con puntajes bajos (expansión urbana, ganadería, función desempeñada por las ONGs, la actividad de la DDCC y la actividad agrícola), siendo la educación, la difusión y la regulación los que pueden ayudar a revertir esta situación. 


\section{c. Acciones e indicadores de calidad ambiental en el parque.}

Tabla 4. Calidad ambiental del PAS.

\begin{tabular}{|l|l|l|l|l|l|l|l|}
\hline $\begin{array}{l}\text { ACCION O ACTIVIDAD } \\
\text { DESARROLLADA }\end{array}$ & $\mathbf{1}$ & $\mathbf{2}$ & $\mathbf{3}$ & $\mathbf{4}$ & $\mathbf{5}$ & $\mathbf{6}$ & COMENTARIO \\
\hline Turismo y recreación * & 90 & 0.6 & 0.4 & 54 & 36 & 18 & Benéfico \\
\hline Agricultura & 65 & 0.3 & 0.6 & 19.5 & 39 & -19.5 & Adverso \\
\hline Ganadería & 60 & 0.2 & 0.7 & 12 & 42 & -30 & Adverso \\
\hline AA.HH. urbano - marginales & 75 & 0.1 & 0.9 & 7.5 & 67.5 & -60 & Adverso \\
\hline Investigación * & 70 & 1.0 & 0.3 & 70 & 21 & 49 & Benéfico \\
\hline Zonificación * $^{*}$ & 80 & 1.0 & 0.2 & 80 & 16 & 64 & Benéfico \\
\hline Educación * & 65 & 0.8 & 0.4 & 52 & 26 & 26 & Benéfico \\
\hline Saneamiento * & 60 & 0.9 & 0.1 & 54 & 6 & 48 & Benéfico \\
\hline Uso canteras & 40 & 0.4 & 1.0 & 16 & 40 & -24 & Adverso \\
\hline Deforestación & 50 & 0.3 & 0.7 & 15 & 35 & -20 & Adverso \\
\hline Reforestación * & 50 & 0.8 & 0.3 & 40 & 15 & 25 & Benéfico \\
\hline Puesta en valor* & 90 & 0.9 & 0.2 & 81 & 18 & 63 & benéfico \\
\hline Participación local * & 65 & 0.7 & 0.4 & 45.5 & 26 & 19.5 & Benéfico \\
\hline Quemas & 40 & 0.2 & 0.7 & 08 & 28 & -20 & Adverso \\
\hline Obtención de leña & 30 & 0.3 & 0.9 & 09 & 27 & -18 & Adverso \\
\hline $\begin{array}{l}\text { Turismo aventura (paseo } \\
\text { caballo y bicicleta) }\end{array}$ & 30 & 0.3 & 0.9 & 09 & 27 & -18 & Adverso \\
\hline Comercio informal & 40 & 0.3 & 0.8 & 12 & 32 & -20 & Adverso \\
\hline TOTAL & $\mathbf{1 0 0 0}$ & & & $\mathbf{5 8 4 . 5}$ & $\mathbf{5 0 1 . 5}$ & $\mathbf{8 3}$ & \\
\hline
\end{tabular}

Fuente: Elaborado en base al sistema Batelle.

\section{Escala de valores:}

0.0 Cambio muy significativo

0.2 Cambio significativo

0.4 Cambio moderado

0.6 Cambio ligero

0.8 Cambio muy ligero

1.0 Ningún cambio
Clave:

1: Peso de la acción

2: Calidad ambiental con la acción

3: Calidad ambiental sin la acción

4: Unidades de impacto con la acción

5: Unidades de impacto sin la acción

6: Cambio neto. 
Previo al análisis del cuadro precedente es preciso aclarar que las 17 acciones 0 actividades desarrolladas dentro del Parque han sido seleccionadas de aquellas que a través de las encuestas aplicadas o de la observación directa y participativa son las más importantes y que ejercen efectos directos sobre la calidad ambiental. Es necesario puntualizar que el sistema empleado es el de Batelle adaptado para el caso del estudio del Parque, por lo que las acciones que resultan siendo de mayor aceptación (aquellas señaladas con el asterisco) fueron evaluados respecto de la unidad, esto es, la valoración determinada para la calidad ambiental, si la acción continuase o se implemente, debe ser restado de uno.

El cuadro evidencia que las acciones que generan efectos adversos son el establecimiento de los asentamientos urbano-marginales, la ganadería, la agricultura, el empleo de canteras, la deforestación, las quemas, la obtención de leña, el turismo de aventura y el comercio informal; aspectos que deberían ser manejados y considerados en el Plan Maestro con fuertes acciones de mitigación. Entre las acciones benéficas de poco peso se tiene al turismo y recreación, la educación, la reforestación y, la participación de la población local; acciones que deben ser seriamente replanteados para un adecuado manejo del PAS.

\subsection{ESTRATEGIAS DE GESTIÓN}

\section{AMBIENTAL. a. Conservación y}

protección ambiental.

Basado en la conservación y protección del ambiente como eje transversal. La protección

del patrimonio natural y cultural, la conciliación de las actividades antrópicas con el entorno del PAS.

\section{b. Participación ciudadana.}

Considerar un nivel de inclusión participativa equitativa con los actores del ámbito de influencia y coordinación constante con los sectores y actores comprometidos en las actividades de conservación del patrimonio natural y cultural, la actividad turística y actividades productivas en general en el ámbito del PAS.

\section{c. Cumplimiento de procedimientos y normas ambientales.}

Implementar y acatar los procedimientos y normas ambientales, de carácter sectorial, regional y local, para garantizar el logro de los objetivos propuestos en el manejo del PAS.

\subsection{Instrumentos de gestión ambiental.}

Para cumplir con los objetivos del PAS se considera importante utilizar como instrumentos de gestión ambiental, una evaluación del impacto ambiental (EIA). Herramienta compatible con la Ley del Sistema Nacional de Evaluación de Impacto Ambiental. Para ello se debe de utilizar como instrumentos:

- Evaluación de Impacto Ambiental y Social, (Estudio de Impacto Ambiental y Social).

- Plan de Manejo Ambiental y Social.

\subsection{Estrategias de gestión}

\section{social. a. De involucramiento de}

\section{actores.}

Se identificará a los beneficiarios directos 0 indirectos, afectados y actores involucrados.

Con ellos se recogerá información de primera fuente, utilizando metodologías apropiadas y participativas para construir el perfil colectivo del contexto socio cultural del PAS. El trabajo deberá realizarse en estrecha relación, coordinación y concertación con los actores sociales, para responder 
sostenidamente a cualquier problema cultural, de género o situación de riesgo social, ambiental o territorial. Asimismo, involucrar a las instituciones públicas y privadas para el logro de los objetivos de los proyectos.

\section{b. Relaciones comunitarias.}

Se mantendrá canales de información en lenguaje sencillo y permanente sobre el manejo del PAS, con los beneficiarios directos, indirectos, afectados y actores sociales involucrados, apelando al derecho de acceso a la información, que a la vez permitirá recoger sus opiniones.

Apoyo a las iniciativas locales de fortalecimiento de las capacidades comunales, y a la revaloración y protección de su organización y sus conocimientos.

\subsection{Plan de manejo.}

a. Plan de Manejo Ambiental.

- Manejo de Residuos Sólidos y líquidos.

- Control de erosión.

- Protección de recursos naturales.

- Control y vigilancia para la prevención de ocupación de derechos de vía (transporte urbano e interprovincial).

- Protección de Recursos arqueológicos.

- Control y cierre de minería no metálica.

- Manejo de campamentos.

- Control de actividades de horse riding.

- Control de actividades de biking.

- Control de actividades agrícolas y pecuarias.

b. Plan de Manejo Social.

- Relaciones Comunitarias con asentamientos humanos y comunidades campesinas.

- Participación Ciudadana (Implementación de Comités de Gestión).
- Programa de Educación

Ambiental forma y no formal.

- Programa de Prevención y de

Contingencias.

\subsection{Propuesta de jardín botánico representativo del PAS.}

Los Jardines Botánicos son considerados como centros de conservación ex situ de la biodiversidad, además de representar lugares de esparcimiento y educación. La forma más eficaz de conservar la biodiversidad es impedir la destrucción o degradación del hábitat, asegurando la conservación de la diversidad del paisaje y de los ecosistemas. En la actualidad ante la pérdida acelerada de los ecosistemas naturales, la conservación ex situ se presenta como una alternativa que además de promover el interés público en la biodiversidad, proporciona material para investigación científica y genera información necesaria que garantice la efectividad de los programas de conservación, tales como mejoramiento genético, propagación de plantas, manejo, introducción y repoblamiento.

La Estrategia Global para la Biodiversidad (WRI, IUCN y PNUMA, 1992) considera como medida 68 la necesidad de convertir a los Jardines Botánicos del mundo en una red importante de conservación ex situ de los recursos de plantas silvestres.

La propuesta del jardín botánico en la zona considera la conservación de bosques relicto de Chachacomo (Escallonia resinosa); queuña (Polylepis incana); qolle (Buddleja coriacea); quishuar (Buddleja incana); molle (Schinus molle); arbustos como el cantu (Cantua buxifolia); el lloque (Kageneckia lanceolata), Tasta (Escallonia mirtilloides); Huayruro

cusqueño (Citharexyllum herrerae); Altensteinia fimbriata (Orchidaceae) entre otras especies presentes en la zona, muchas de ellas categorizadas como 
amenazadas por DS.

043-2006-AG., y también consideradas como sensibles a los impactos. Estas especies conservadas en el Jardín Botánico podrían constituir refugio de especies animales,

especialmente de la ornitofauna local.
En base al estudio realizado en campo se ha determinado un área en la zona de Kallachaca por reunir condiciones climáticas, topográficas, edáficas y florísticas adecuadas, la misma cubre un área de 9.5 hectáreas.

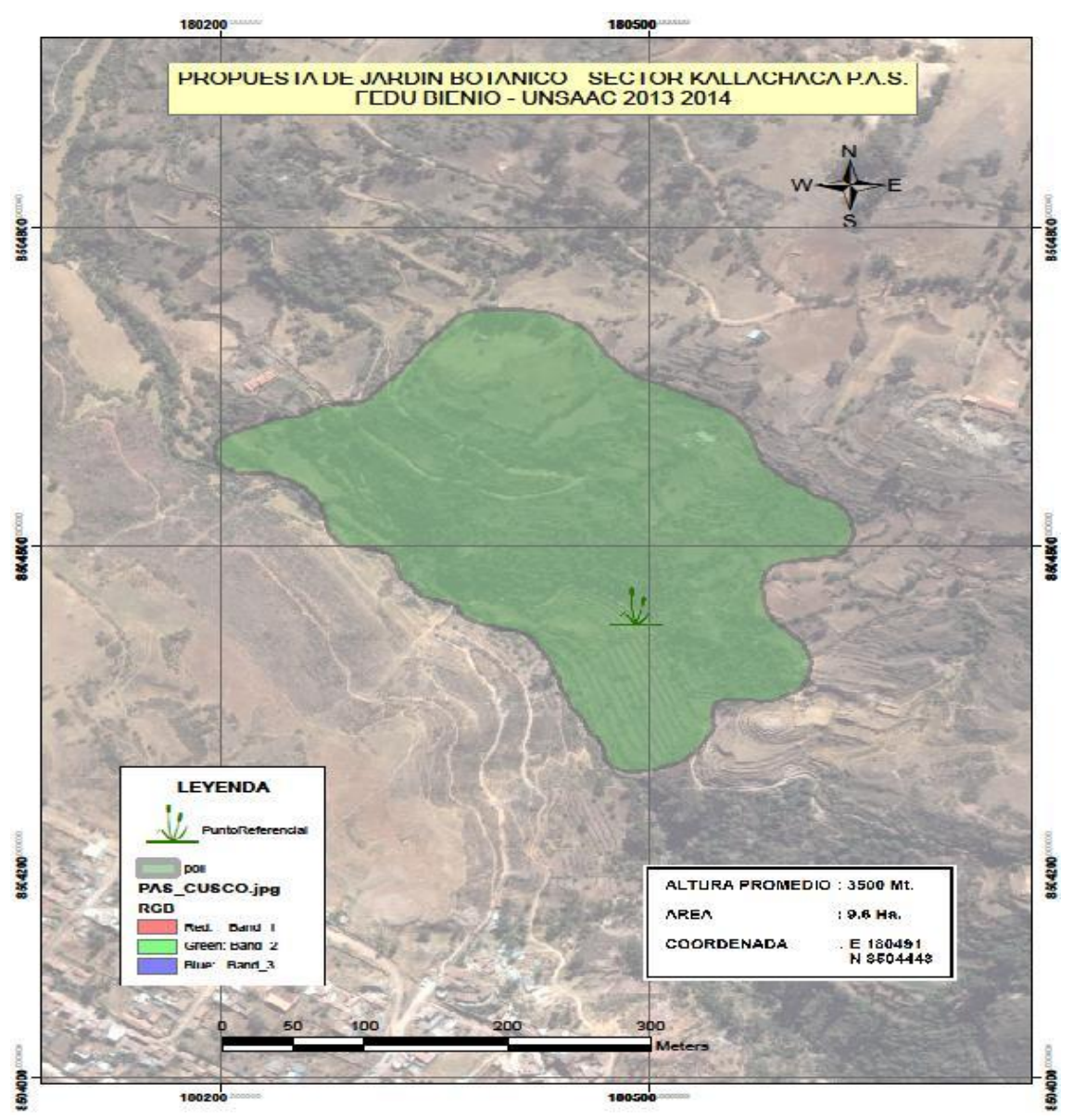

Figura 2. Ubicación del Jardín Botánico del PAS. 


\section{CONCLUSIONES:}

1. En términos globales, la cobertura vegetal del Parque se halla distribuida en la forma siguiente:

a. Pastizales naturales,

b. Bosques de especies exóticas (eucalipto y pino),

c. Cultivos,

d. Matorrales.

e. La composición de la flora y la diversidad de las especies muestran variaciones de acuerdo a la distribución altitudinal así como a factores climáticos y edáficos.

2. Las actividades que generan los mayores impactos negativos en el PAS son: expansión urbana con invasión de áreas intangibles; actividad agrícola con uso de agroquímicos; actividad pecuaria; quemas e incendios; obtención de leña y biodiversidad; construcción de trochas carrozables y caminos peatonales; actividades de recreación poco planificada y sin control adecuado como el biking y la cabalgata que generan erosión de suelos.

3. En el PAS se emplea maquinaria pesada como el tractor, en el 7\% de las parcelas agrícolas y en todas las parcelas utilizan agroquímicos.

4. De las 24 prácticas desarrolladas dentro del PAS, 11 no son compatibles, 6 son

limitadamente compatibles y 6 se hallan dentro de las prácticas compatibles. 4 prácticas (modificación del recurso hídrico, conducción del agua fuera del PAS, uso de agroquímicos y, la formación de nuevos asentamientos humanos) se hallan en el umbral de las prácticas que generan los mayores impactos y 4 que son totalmente compatibles. Seis prácticas de manejo se hallan en el valor intermedio (03), lo que significa que su ejercicio debe ser vigilado y poseer acciones de mitigación.

5. La valoración de los impactos mediante el método Battelle, evidencia que las acciones que generan impactos adversos son el establecimiento de los asentamientos urbanomarginales, la ganadería, la agricultura, el empleo de canteras, la deforestación, las quemas, la obtención de leña, el turismo de aventura y el comercio informal; aspectos que deberían ser manejados y considerados en el Plan Maestro con fuertes acciones de mitigación. Entre las acciones benéficas de poco peso se tiene al turismo y recreación, la educación, la reforestación y, la participación de la población local.

6. Para conservar la flora representativa del PAS es necesario el establecimiento de un jardín botánico cuyas ubicaciones son planteadas en el trabajo.

\section{RECOMENDACIONES.}

En el territorio del Parque Arqueológico de Saqsaywaman se hallan además de importantes valores históricos, culturales y arqueológicos, muestras representativas de la flora andina, recursos genéticos y procesos ecológicos; por lo tanto, en el Parque se debe desarrollar no sólo los objetivos de la conservación del patrimonio cultural y natural, sino también los de educación, investigación, recreación y turismo compatibilizando el uso de los recursos naturales existentes para el desarrollo de las comunidades campesinas localmente asentadas primero, luego, que el Parque constituya una zona que aporte al desarrollo regional y nacional. Para ello sugerimos las siguientes recomendaciones: 


\section{Primera.}

Elaborar un plan de reordenamiento territorial que abarque las cuencas de Saphy, Chacán, Choquechaca, Inquiltambo y Tenería (Pumamarca) que incluya áreas urbanas y rurales, detalle la capacidad de uso mayor de los suelos y su vocación productiva, zonas de protección, áreas arqueológicas, históricas, ecológicas, expansión urbana, recreación, reforestación, zonas de riesgo y zonas intangibles. Elaborado la propuesta de acondicionamiento territorial formular el replanteamiento de los límites del PAS.

\section{Segunda.}

Elaborar el Plan de Manejo del PAS que involucre acciones orientadas a la conservación del patrimonio cultural y natural, puesto que no obstante, las delimitaciones actualmente existentes, el Parque está conectado a su entorno a través de relaciones ecológicas, económicas, sociales y culturales que la afectan o que la potencian.

Considerando los problemas analizados y su tendencia creciente hacia el deterioro de los recursos existentes dentro del Parque, debe ser considerado prioritario la elaboración del Documento que rija el manejo de los recursos del Parque así como efectuar su gestión.

Entre los ejes más importantes que debe contener el Plan de Manejo se señala:

a. Recuperar la cobertura vegetal y disminuir la erosión, mediante programas de reforestación, prácticas de conservación de suelos, técnicas de control de erosión, sistemas de irrigación apropiados, control de incendios, pastoreo rotativo, etc.

b. Zonas de manejo o zonificación del Parque que tendría como finalidad la protección y el uso adecuado de los recursos existentes. La zonificación permitirá no sólo el uso sostenido de los recursos existentes sino una adecuada gestión y control de las acciones a ser desarrolladas.

c. Elaboración de Reglamentos para la ejecución y operatividad de las acciones a ser propuestas y que a su vez regulen las acciones $y$ actividades dentro del Parque.

d. Elaborar políticas de desarrollo y gestión ambiental del PAS.

e. Educación ambiental orientada al respeto, identificación de los valores culturales y naturales existentes y, al uso sostenido de los recursos existentes dentro del PAS.

f. Investigación, que incluya estudios arqueológicos, geológicos, ecológicos, sociales y económicos incluyendo la puesta en valor.

g. Desarrollo rural apropiado vinculado al mejor uso del suelo, agua, cobertura vegetal, saneamiento ambiental, educación, salud, etc. que incluya asesoramiento técnico para el manejo de los recursos naturales y la producción agrícola y pecuaria.

\section{BIBLIOGRAFÍA:}

1. Banco Mundial. (1982). Consideraciones Ambientales y Ecología en Proyectos de Desarrollo Económico. Washington.

2. Canter, Larry W. (1980). Environmental Impact Assessment. Mc Graw-Hill Book Company. N. York.

3. Canter, L. 1999. Manual de Evaluación de Impacto Ambiental. Mc Graw-Hill Book Company. Madrid. España.

4. Ministerio del Ambiente. (2015). Guía de Inventario de la flora y vegetación. Lima

5. IUCN-PNUMA. (1990). Manejo de Áreas Protegidas en los Trópicos. Gland, Suiza. 
6. Miller, K.R. - Thelen, K.D. (1979). Manejo y Desarrollo Integral de las Áreas Naturales y Culturales. INDAF/FAO-CUB/RLAT. Santiago de Chile.

7. Munn, R.E. (1979). Environmental Impact Assessment: Principles and Procedures. Scope Report 5. Toronto.

8. Ricalde Pérez, D. (1990). Nuevos registros de aves para el valle del Cusco y alrededores. Tesis UNSAAC.

9. Sánchez, V.- Sejenovich, H. (1983). En Torno al Ecodesarrollo. Universidad Estatal a Distancia. San José.

10. Thelen, K.D. Dalfelt, A. (1983).

Políticas para el Manejo de áreas

Silvestres. Universidad Estatal a

Distancia. San José. 


\section{ANEXO I: MAPAS EN EL ÁMBITO DE TRABAJO.}

Mapa 01. Ubicación del área de estudio.

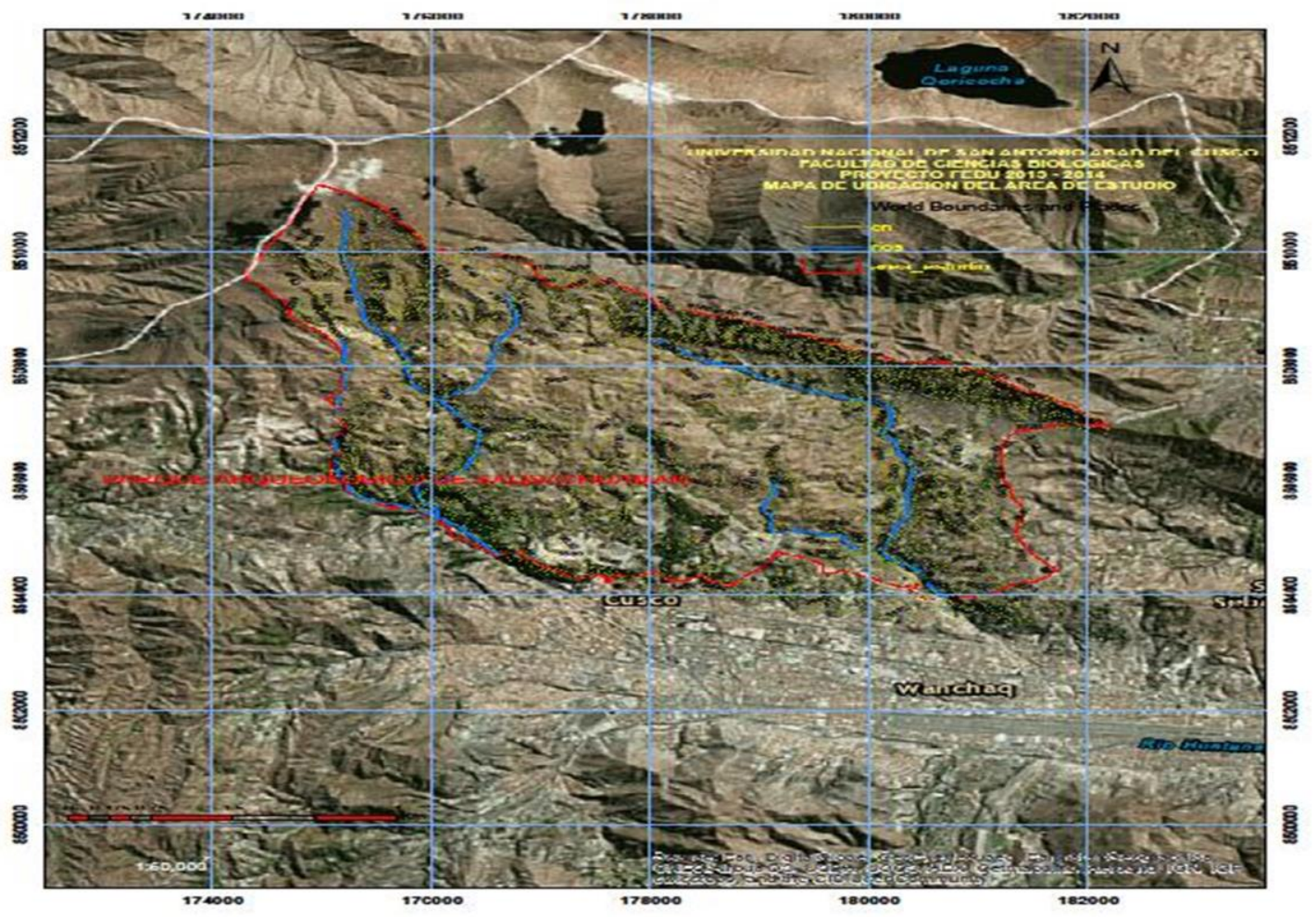

Fuente. Elaborado por el equipo de trabajo.

Mapa $N^{\circ}$ 02. Zonas de Vida Natural en el PAS

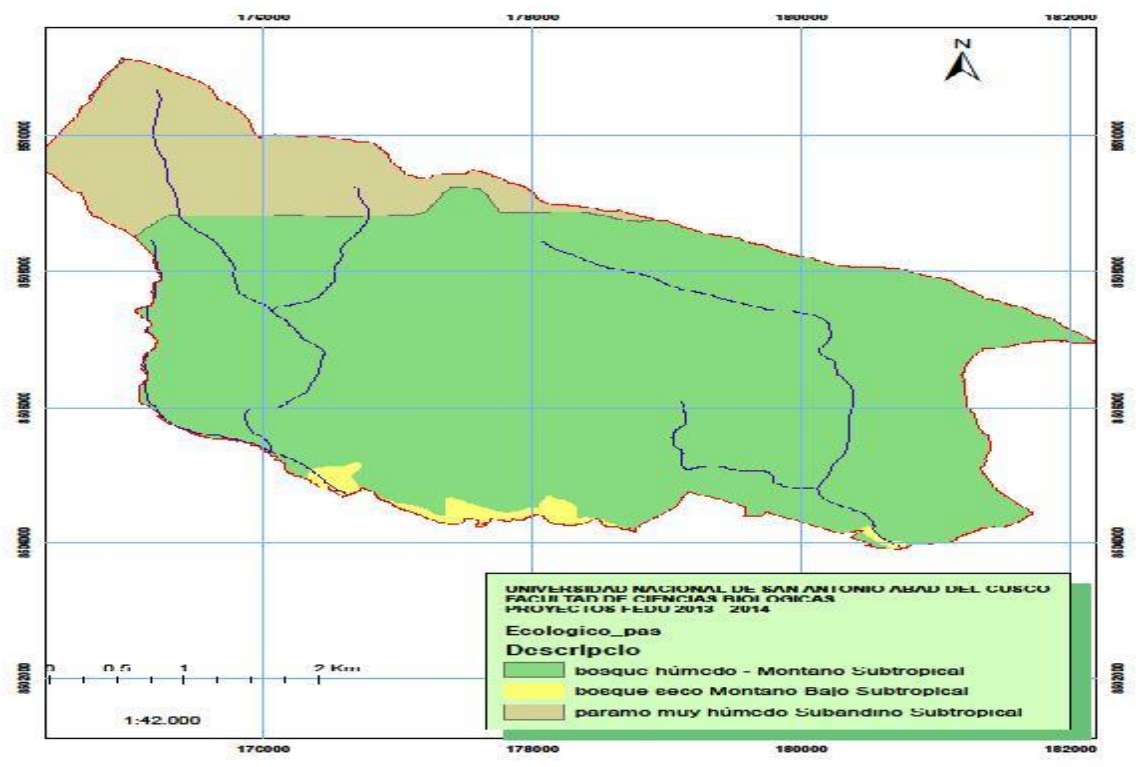

Fuente. Elaborado por el equipo de trabajo. 
Mapa 03. Erosión de suelos en el PAS

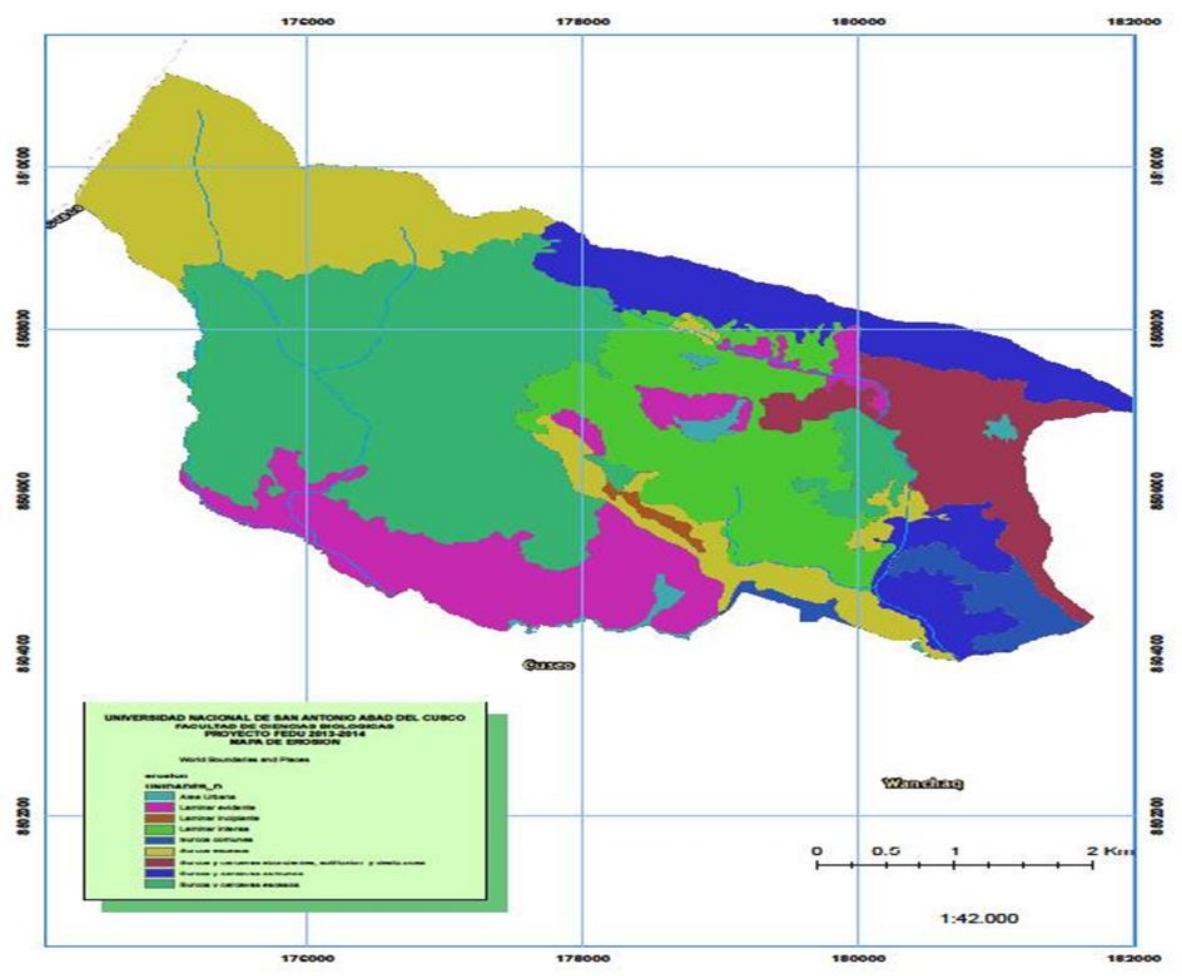

Fuente. Elaborado por el equipo de trabajo. 


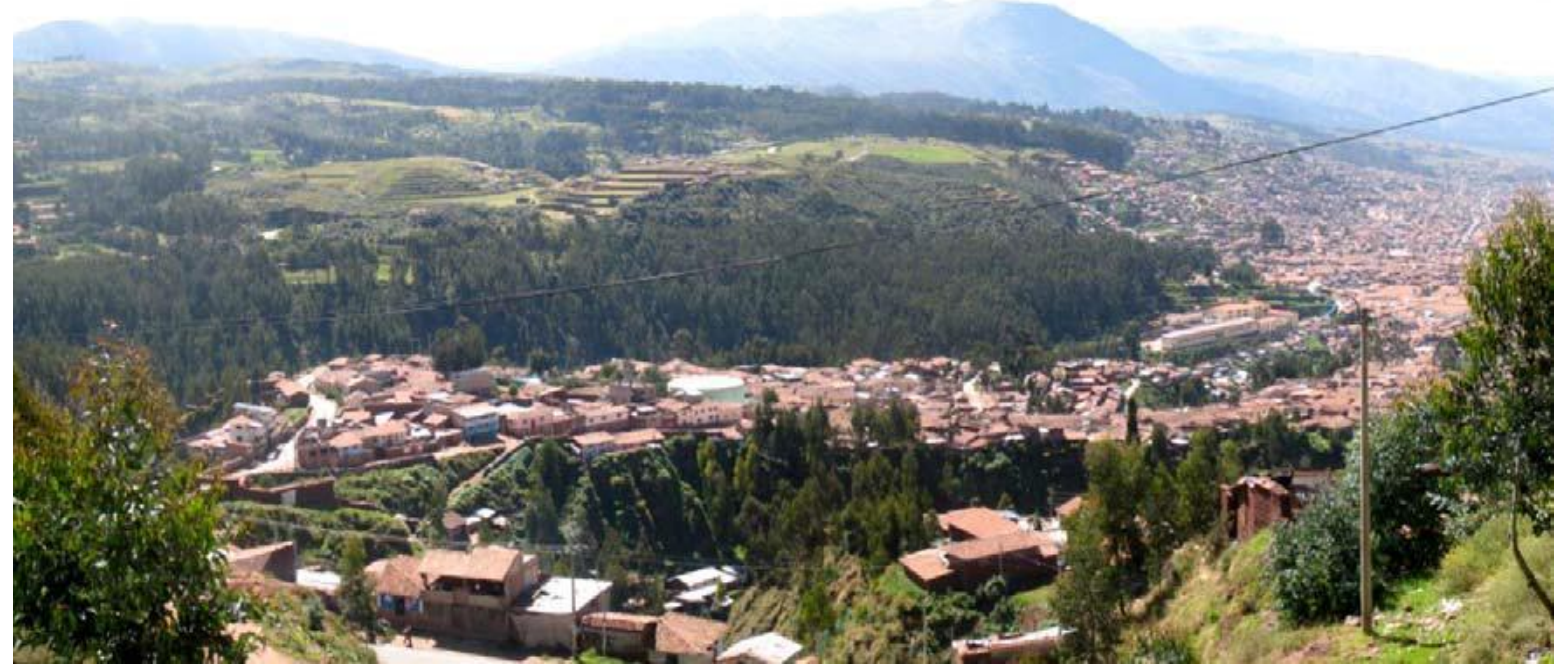

Foto 01. EI PAS en la zona media, donde se ubican la mayor parte de los monumentos arqueológicos ha sido forestada con la especie exótica Eucaliptus globulus; habiéndose modificado el paisaje y la flora nativa.
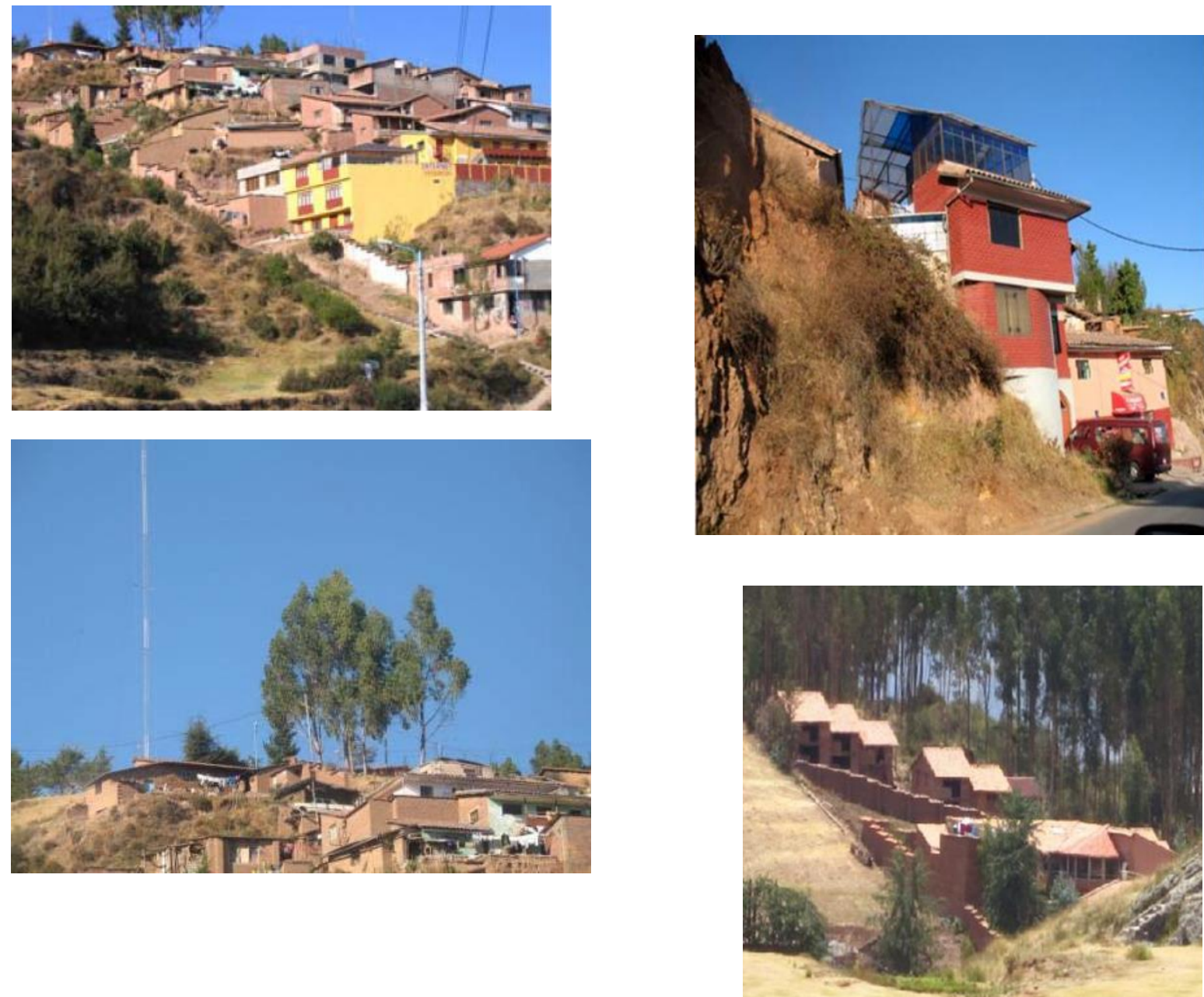

Fotos $02 ; 03 ; 04$ y 05 . La rápida urbanización ha traído consigo el hacinamiento y no sólo la invasión del PAS, sino deterioro del paisaje, generación de residuos sólidos y contaminación del agua y suelo. 

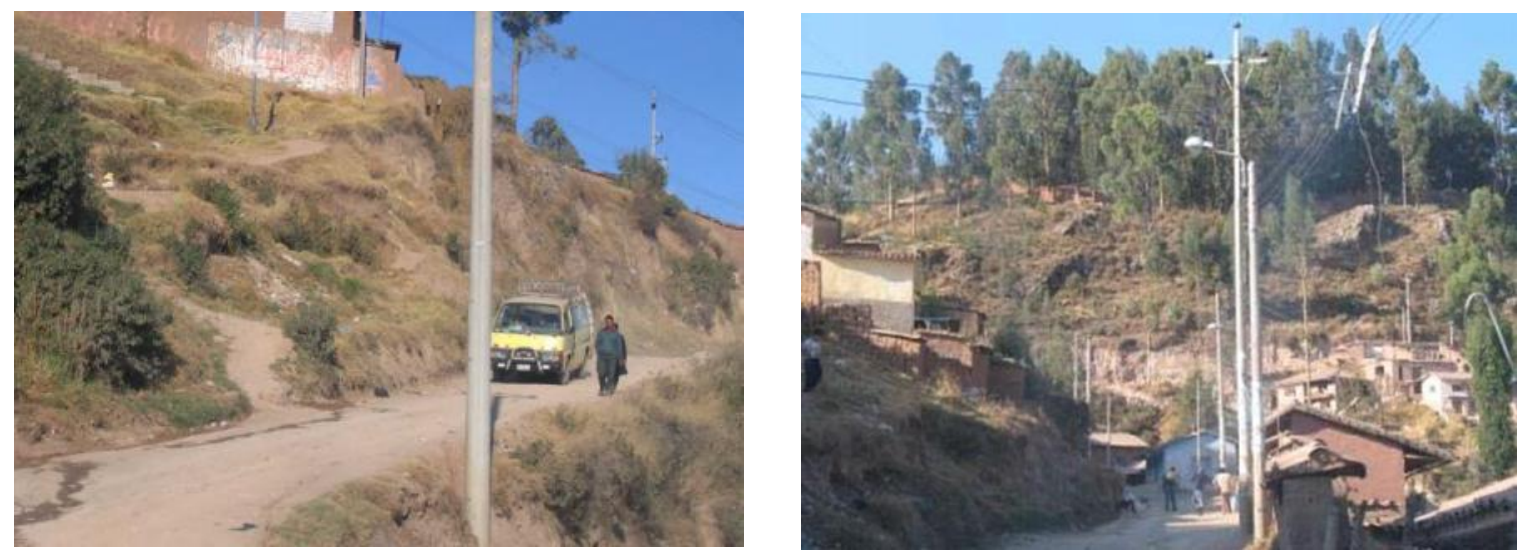

Fotos 06; 07 y 08. La apertura de caminos y vías carrozables generan impactos negativos provocando erosión

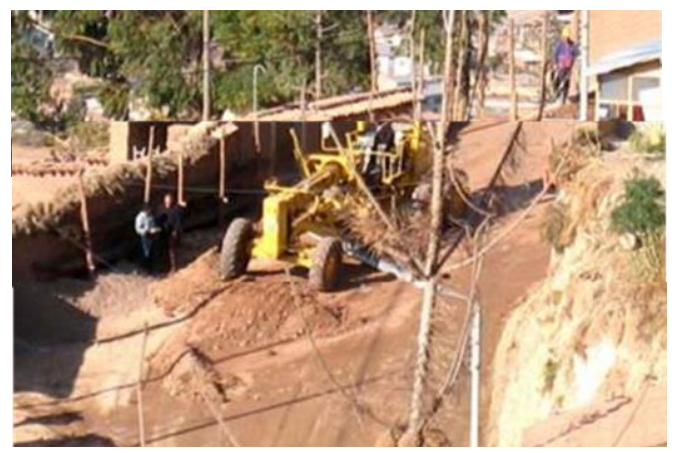

Foto 09. La ganadería exótica, provoca sobrepastoreo y deterioro de la cubierta vegetal. 

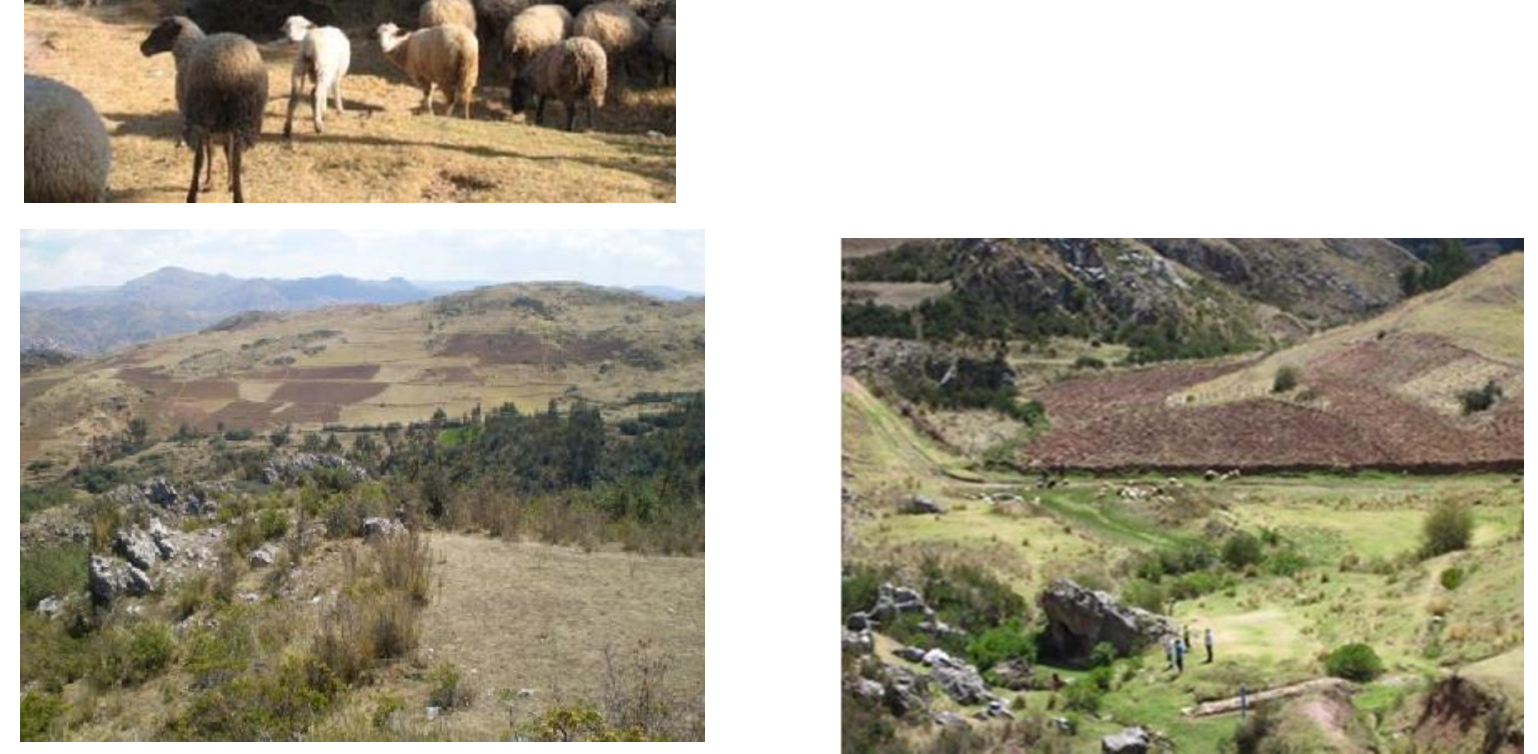

Fotos 10 y 11. La agricultura con surcos a favor de la pendiente arrastra sólidos y genera erosión laminar. 

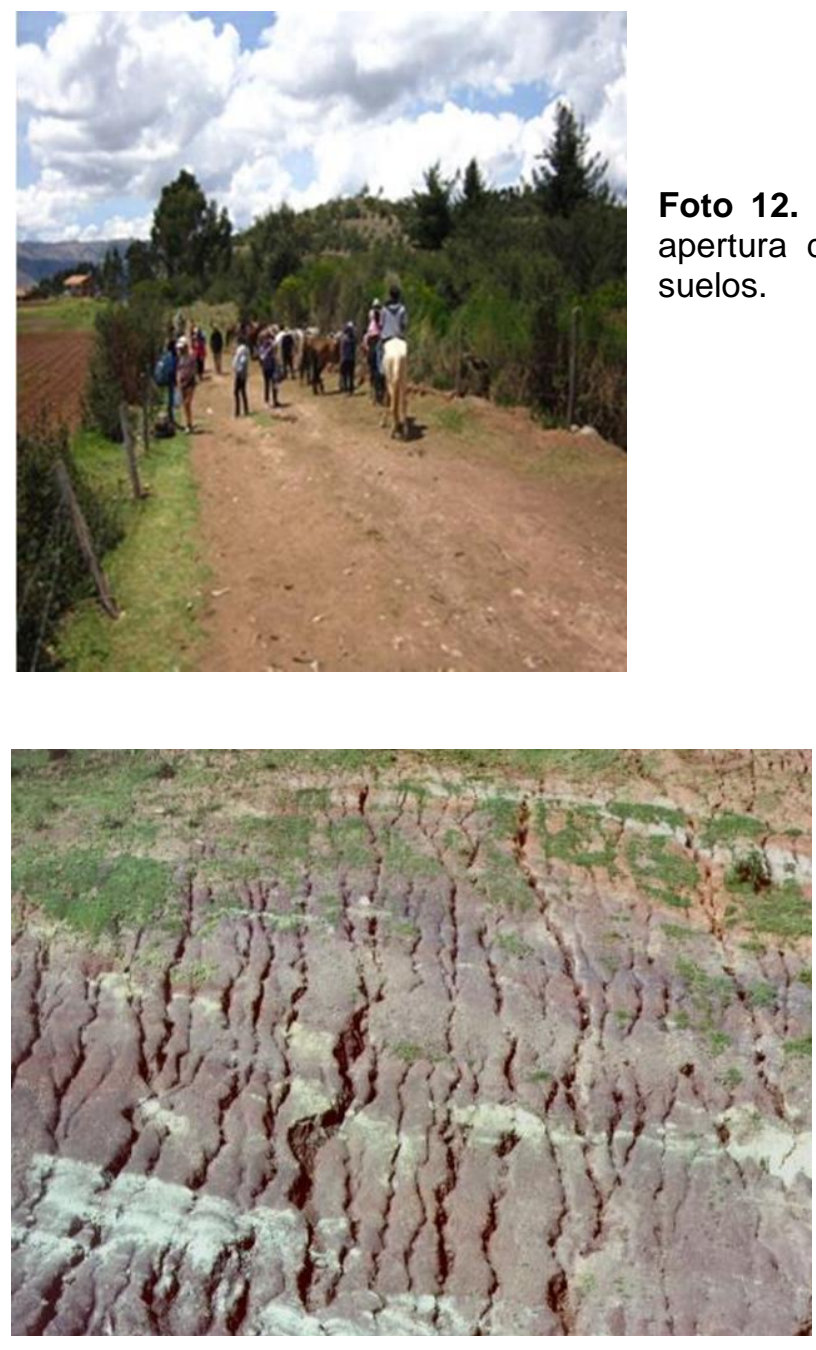

Foto 13. Debido a la falta de cobertura vegetal y al intenso sobreuso, se observa una erosión por surcos e incluso procesos de salinización.

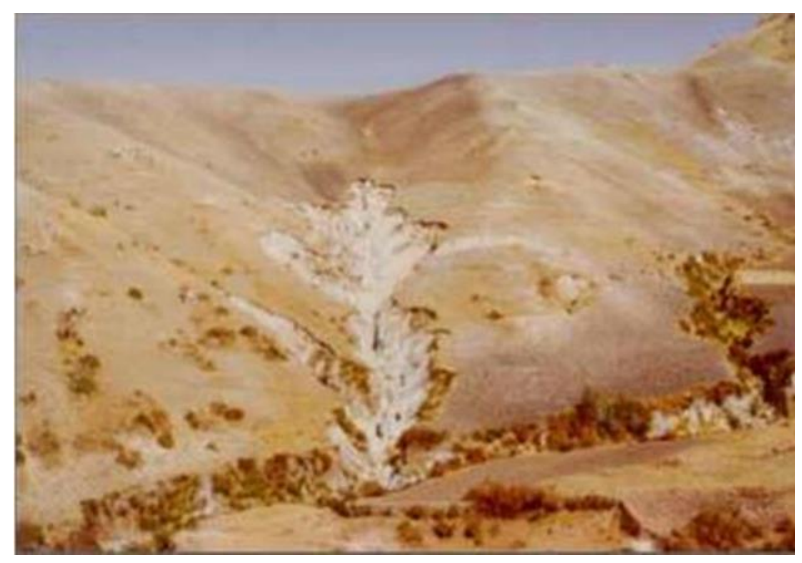

Foto 14. El carcavamiento es un indicador de pérdida de suelos y deterioro del paisaje. Muy común en el PAS 

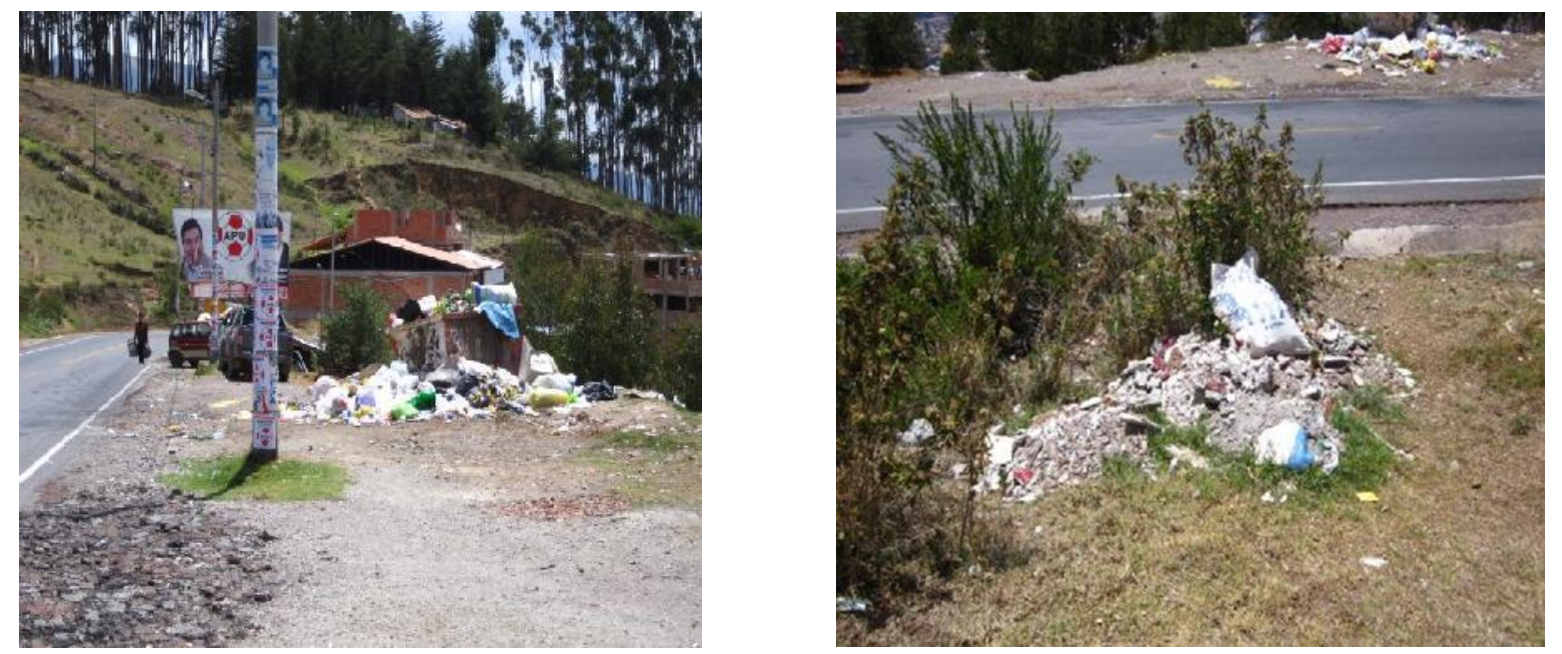

Fotos 15 y 16. La no gestión de residuos sólidos genera contaminación de agua y suelos y afecta a la salud pública. 